\title{
MUTASUON KALKITUSKOKEIDEN TULOKSIA LETEENSUOLTA
}

\author{
YRJÖ PESSI \\ Suoviljelysyhdistys, Leteensuon koeasema
}

Saapunut 6. 8. 1959

Eri turvelajien kalkkipitoisuus vaihtelee. Rahkaturpeen kalkkipitoisuus on pienempi kuin esimerkiksi ruskosammalsaraturpeen. Turpeen kalkkipitoisuuteen saattavat vaikuttaa myös muut tekijät, kuten ympäristöstä valuvien vesien tuoma kalkki. Suoviljelysten kalkin tarve saattaa siis vaihdella paljon.

Esillä olevassa tutkimuksessa selostetaan Leteensuon koeasemalla järjestettyjen kalkituskokeiden tuloksia mutasuon osalta. Rahkasuolla järjestettyjen kalkituskokeiden tuloksia on äskettäin selostettu muissa yhteyksissa $(4,5)$. Nyt selostettavat tulokset täydentävät myös AntTisen $(1,2)$ tutkimuksia. Saraturvesuon kalkitus- ja lannoituskokeen tuloksia käsittelevässä tutkimuksessa ANTTINEN (2) mainitsee myös muita kalkituskysymystä koskettelevia tutkimuksia, mistä johtuen esillä olevassa työssä jätetään tämä tekemättä ja rajoitutaan lähinnä Leteensuon koeaseman koetuloksien selostamiseen. Aikaisemmin ovat näitä tuloksia käsitelleet TUorila (7) ja Vesikivi $(9,10)$.

\section{Koealue ja koesunnitelmat}

Suoalueesta on yksityiskohtaisen kasvipeitekuvauksen tehnyt LINDBERG (3). Geologista puolta on selvittänyt Rindell (6). Koealueen turve on metsäsaraturvetta. Suotyyppi ennen raivausta on ollut ruoho- ja heinäkorpi.

Koealueiden läheisyydestä on RINDELL tutkinut turpeen kemiallisia ominaisuuksia (8). Nämä tiedot ilmenevät yksityiskohtaisemmin Vesikiven (8, s. 32) tutkimuksesta. Mainittakoon vain, että $20 \mathrm{~cm}$ paksussa maakerroksessa määritysten mukaan on $\mathrm{CaO}$ ollut $5858 \mathrm{~kg} / \mathrm{ha}$, vastaten siis lähes 12 tn kalkkikivijauhemäärän sisältämää $\mathrm{CaO}$-pitoisuutta.

Vuonna 1908 aloitetun kokeen ovat perustaneet A. Rindell ja E. F. Simola sekä vuonna 1932 aloitetun A. Vesikivi. Kokeita ovat hoitaneet E. F. Simola (1908-1917), E. A. Malm (1918-1919), A. Vesikivi (1920-1943), J. Törmä (1944), ja U. E. Hirvensalo (1945-1946). 
Leteensuon koeaseman mutasuon kalkituskysymystä tarkastellaan seuraavassa kahden, kauemmin jatkuneen kalkituskokeen perusteella.

Kalkituskoe 1. Koealue on raivattu viljelykseen vuonna 1906 sekä salaojitettu lautaputkia käyttäen. Fosfori- ja kalilannoitus on annettu vuosittain. Fosfaattilannoitus on vastannut noin $200-300 \mathrm{~kg}$ superfosfaattia hehtaarille sekä kalilannoitus $100-200 \mathrm{~kg} 50 \%$-kalisuolaa. Kivennäismaata ei ole käytetty maanparannusaineena. Kalkitukset on koesuunnitelman mukaisesti $(0,100,2000$ ja $3000 \mathrm{~kg} /$ ha sammutettua kalkkia) annettu neljä kertaa, nimittäin vuosina 1907, 1911, 1920 ja 1940.

Kalkituskoe 2. Alueen raivaus viljelykseen on tehty 1904 . Seuraavana vuonna on lisätty maanparannusaineeksi $400 \mathrm{~m}^{3} /$ ha hiekkaa. Viljelys on aloitettu samana vuonna. Kalkituskoe on järjestetty vasta 1932 , jolloin kalkitus suoritettiin koesuunnitelman mukaan, siis $0,1000,2000$ ja $3000 \mathrm{~kg}$ sammutettua kalkkia hehtaarille. Vuotuinen lannoitus on ollut samankaltainen kuin edellä mainitussa kokeessakin.

TUoRILA (7) on tutkinut millä tavoin maan happamuus on muuttunut vuonna 1908 aloitetussa kokeessa kalkituksen johdosta. pH-luku oli ilman kalkkia 4.9 sekä kalkituksen lisääntyessä $5.25,5.55$ ja 6.33 .

\section{Satotulokset}

Koevuosien sääolot on selostettu eräässä aikaisemmassa tutkimuksessa (5).

Vuosittaiset satotulokset ilmenevät liitteistä I ja II. Koetuloksia käsiteltäessä on vuosittaisten keskiarvojen lisäksi laskettu merkitsevät satoerot vain silloin, kun F-arvo on saanut vähintäin yhden tähden.

Taulukko 1. Kalkituskoe 1. Keskimääräiset heinäsadot vuotta kohden kg/ha (15 vuotta).

Table 1. Liming test $\mathrm{N}$ :o. 1. Average annual crop yields, kg/ha (15 years).

\begin{tabular}{ccc}
$\begin{array}{c}\text { Sammutettua kalkkia kg/ha } \\
\text { Hydrate of lime, } \mathrm{kg} / \mathrm{ha}\end{array}$ & $\begin{array}{c}\text { Sato } \\
\text { Crop yield }\end{array}$ & $\begin{array}{c}\text { Sadon lisäys } \\
\text { Increase in crop yield }\end{array}$ \\
\hline 0 & 5570 & - \\
1000 & 5620 & 50 \\
2000 & 5510 & -60 \\
3000 & 5540 & -30
\end{tabular}

Taulukko 2. Kalkituskoe 2. Keskimääräiset heinäsadot vuotta kohden kg/ha (5 vuotta).

Table 2. Liming test No 2. Average annual crop yields, $\mathrm{kg} / \mathrm{ha}$ (5 years).

\begin{tabular}{ccc}
$\begin{array}{c}\text { Sammutettua kalkkia } \mathrm{kg} / \mathrm{ha} \\
\text { Hydrate of lime, } \mathrm{kg} / \mathrm{ha}\end{array}$ & $\begin{array}{c}\text { Sato } \\
\text { Crop yield }\end{array}$ & $\begin{array}{c}\text { Sadon lisäys } \\
\text { Increase in crop yield }\end{array}$ \\
\hline 0 & 6470 & - \\
1000 & 6320 & -150 \\
2000 & 6520 & 50 \\
3000 & 6490 & 20
\end{tabular}


Nurmet. Taulukoissa 1 ja 2 esitetään keskimääräiset heinäsadot vuotta kohden. Heinänurmet ovat olleet timoteivaltaisia. Tuloksista ilmenee, ettei kalkitus ole nostanut eikä vähentänyt satoja. Ruukin suoviljelyksellä, jossa maan kalkkipitoisuus oli ennen erään lannoitus- ja kalkituskokeen aloittamista n. $4500 \mathrm{~kg} \mathrm{CaO} / \mathrm{ha}$, on sen sijaan saatu kalkituksella heinäsatojen lisäyksiä (2, s. 14).

Viljat. Taulukossa 3 ja kuvassa 1 esitetään kauran ja ohran keskimääräisiä satotuloksia vuotta kohden. Kalkituksen voidaan todeta alentaneen kauran jyväsatoja, kuten oli laita myös Ruukin kokeessa $(2, \mathrm{~s}$. 16). Sen sijaan ohran jyväsatoon ei kalkitus ole vaikuttanut kohottavasti eikä alentavastikaan.

Taulukko 3. Kalkituskoe 1. Keskimääräiset kauran (8 vuotta) ja ohran (7 vuotta) jyvä- ja olkisadot vuotta kohden $\mathrm{kg} / \mathrm{ha}$.

Table 3. Liming test No. 1. Average annual grain and straw yields of oats (8 years) and barley (7 years) kg per hectare.

\begin{tabular}{lccc}
\hline Sammutettua kalkkia $\mathrm{kg} / \mathrm{ha}$ & Jyväsato & Sadon lisäys & Olkisato \\
Hydrate of lime, $\mathrm{kg}$ per hectare & Grain yield & Incr. in yield & Straw yield \\
\hline
\end{tabular}

\begin{tabular}{rccc}
\multicolumn{5}{c}{ Kaura-Oats } \\
0 & 2970 & - & 5260 \\
1000 & 2960 & -10 & 5220 \\
2000 & 2750 & -220 & 5212 \\
3000 & 2470 & -500 & 4825 \\
& & $354^{*}$ & \\
& & $481^{* *}$ & \\
& & $649 * * *$ & \\
& & & \\
& & & 4750 \\
1000 & 1970 & - & 4720 \\
2000 & 1950 & -20 & 5170 \\
3000 & 2020 & 50 & 4950
\end{tabular}

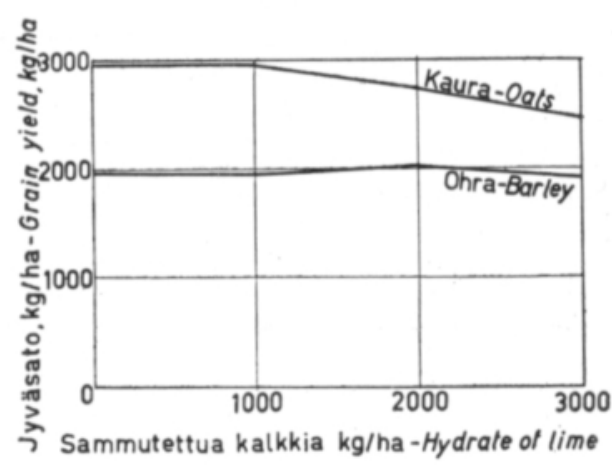

Kuva 1. Keskimääräiset jyväsadot vuotta kohden. Kalkituskoe 1. Fig. 1. Average annual grain yields. Liming test no. 1. 
Juurikasvit. Taulukossa 4 ja kuvassa 2 esitetään juurikasvien satoja. Voidaan havaita, että sokerijuurikkaan juurisatoja ovat pienemmät kalkitukset lisänneet, mutta suurin jo alentanut jälleen. Lantun ja turnipsin juurisatoihin ei kalkituksella ole ollut selvää vaikutusta. Kaikkien juurikasvien naattisadoille on ominaista, että kalkitus on vähentänyt niitä.

Taulukko 4. Kalkituskoe 1. Keskimääräiset sokerijuurikkaan (5 vuotta), lantun (5 vuotta) ja turnipsin (4 vuotta) juuri- ja naattisadot vuotta kohden $\mathrm{kg} / \mathrm{ha}$.

Table 4. Liming test No. 1. Average annual root and tops yields of sugar beet (5 years), swede (5 years) and turnip (4 years) $\mathrm{kg}$ per hectare.

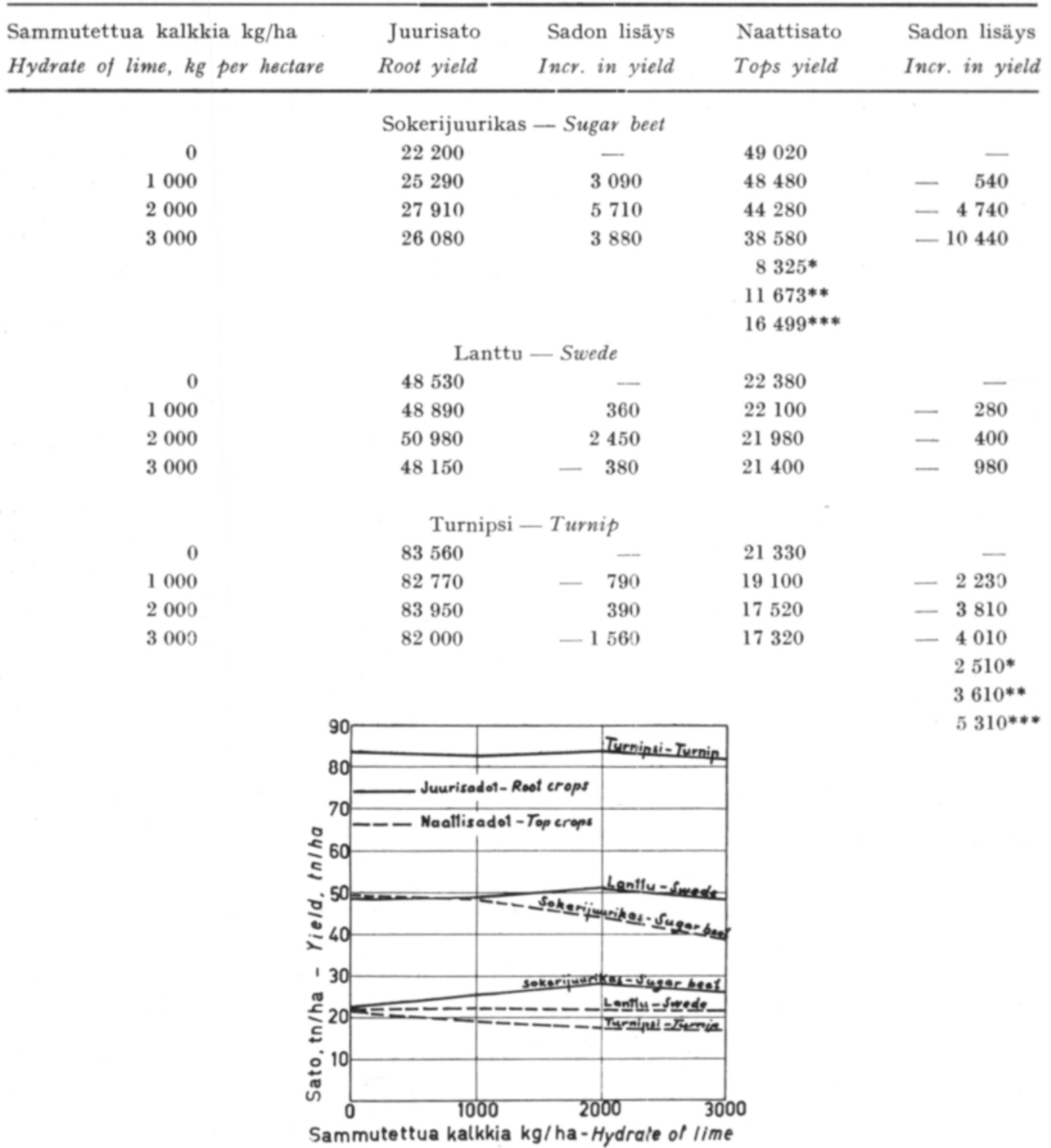

Kuva 2. Juurikasvien keskimääräiset juuri- ja naattisadot. Kalkituskoe 1.

Fig. 2. Average annual root and tops yields of root crops. Liming test no. 1 . 
Sadon laatu. Sadon laatua koskevia tutkimuksia on suoritettu vähän. Kahdelta vuodelta on olemassa vain sokerijuurikkaan sokeripitoisuusmääritykset. Vuonna 1924 oli sokeripitoisuus ilman kalkkia olevassa koejäsenessä $15.6 \%$ ja kalkituksen lisääntyessä $15.6,15.6$ ja $14.4 \%$. Vuonna 1932 olivat vastaavat luvut $16.7,14.0,14.8$ ja $16.0 \%$. Sanottavaa vaikutusta ei kalkituksella ole siis sokeripitoisuuteen ollut.

\section{$P \ddot{a} \ddot{a} t e l m \ddot{a} t$}

Mutasuolla, jonka turve on metsäsaraturvetta ja jossa $20 \mathrm{~cm}$ syvässä kerroksessa on ollut $\mathrm{CaO}$ lähes $6000 \mathrm{~kg} / \mathrm{ha}$, on kalkituksen vaikutus ollut erilainen koekasvista riippuen. Timoteivaltaisen heinänurmen, ohran jyvä- sekä lantun ja turnipsin juurisatoihin ei kalkituksella ole ollut sanottavaa vaikutusta puoleen eikä toiseen. Sokerijuurikkaan juurisatoja on kalkitus kohottanut, joskin suurin määrä jo vaikuttaa alentavasti. Kauran jyväsatoa on kalkitus alentanut selvästi. Myös juurikasvien naattisadot ovat alentuneet kalkituksen lisääntyessä.

Liite 1. Kalkituskoe 1. Sadot vuosittain $\mathrm{kg} / \mathrm{ha} \times 10^{-1}$.

Appendix I. Liming test No. 1. Annual yields, $\mathrm{kg} / \mathrm{ha} \times 10^{-1}$.

\begin{tabular}{|c|c|c|c|c|c|c|c|c|c|}
\hline & & & \multicolumn{7}{|c|}{ Samnıutettua kalkkia, $\mathrm{kg} / \mathrm{ha}-$ Hydrate of lime, $\mathrm{kg} / \mathrm{ha}$} \\
\hline & & & & & & 0 & 1000 & $20 C 0$ & 3000 \\
\hline \multirow[t]{2}{*}{1908} & Kaura & jyviä & - Oats & & grain & 217 & 187 & 214 & 222 \\
\hline & & olkia & & & straw & 271 & 247 & 262 & 266 \\
\hline \multirow[t]{2}{*}{1909} & Ohra & jyviä & - Barle & & grain & 281 & 240 & 233 & 212 \\
\hline & & olkia & & & straw & 266 & 241 & 235 & 271 \\
\hline \multirow[t]{2}{*}{1910} & Lanttu & juuria & - Swed & & roots & 4597 & 4548 & 5631 & 5369 \\
\hline & & naatteja & & & tops & 940 & 1052 & 1341 & 1400 \\
\hline 1911 & Kesanto & & - Fallor & & & & & & \\
\hline 1912. & 1 nurmi & heiniä & $-1 s t y e$ & ear ley & hay & 373 & 434 & 490 & 518 \\
\hline 1913 & 2. & , & $-2 n d$ & , & , & 415 & 373 & 412 & 421 \\
\hline 1914 & 3. & , & $-3 r d$ & " & - & 480 & 445 & 501 & 496 \\
\hline 1915 & 4. & , & $-4 t h$ & $\cdot$ & , & 568 & 607 & 555 & 558 \\
\hline 1916 & 5. & , & $-5 t h$ & , & , & 534 & 534 & 516 & 463 \\
\hline 1917 & 6. & , & $-6 t h$ & , & , & 467 & 501 & 460 & 410 \\
\hline 1918 & 7. & , & $--7 t h$ & , & , & 365 & 376 & 359 & 363 \\
\hline 1919 & 8. & , & $-8 t h$ & * & " & 502 & 473 & 427 & 430 \\
\hline \multirow[t]{5}{*}{1920} & Hernekaura & vihanta & - Peas & and oats & green & 482 & 406 & 356 & 311 \\
\hline & Herne & siemeniä & - Peas & & seed & 150 & 140 & 146 & 161 \\
\hline & & varsia & & & haulm & 250 & 225 & 282 & 248 \\
\hline & Kaura & jyviä & - Oats & & grain & 342 & 336 & 286 & 266 \\
\hline & & olika & & & straw & 505 & 479 & 437 & 398 \\
\hline \multirow[t]{4}{*}{1921} & Hernekaura & jyviä & - Peas & and oats & grain & 361 & 288 & 301 & 201 \\
\hline & & olkia & & & straw & 533 & 569 & 503 & 378 \\
\hline & Puna-apila & & $-\operatorname{Red} c$ & clover & & 328 & 361 & 369 & 352 \\
\hline & Alsikeapila & & - Alsik & e clocer & & 250 & 293 & 267 & 242 \\
\hline \multirow[t]{2}{*}{1922} & Lanttu & juuria & - Swede & & roots & 5970 & 6520 & 6600 & 6380 \\
\hline & & naatteja & & & tops & 3660 & 3350 & 3310 & 3240 \\
\hline
\end{tabular}


Sammutettua kalkkia, $\mathrm{kg} / \mathrm{ha}-\mathrm{Hy}$ drate of lime, $\mathrm{kg} / \mathrm{ha}$

$0 \quad 1000$

2000

3000

\begin{tabular}{|c|c|c|c|c|c|c|c|c|c|}
\hline & \multirow[t]{2}{*}{ Turnipsi } & \multirow{2}{*}{$\begin{array}{l}\text { juuria } \\
\text { naatteja }\end{array}$} & \multirow{2}{*}{\multicolumn{2}{|c|}{ - Turnip }} & roots & 10500 & 10900 & 11070 & 11240 \\
\hline & & & & & tops & 2830 & 2570 & 2130 & 2120 \\
\hline & \multirow[t]{2}{*}{ Sokerijuurikas } & juuria & \multirow{2}{*}{\multicolumn{2}{|c|}{ - Sugar beet }} & roots & 2010 & 1920 & 1930 & 1720 \\
\hline & & naatteja & & & tops & 6490 & 6200 & 5750 & 4030 \\
\hline \multirow[t]{4}{*}{1923} & \multirow[t]{2}{*}{ Ohra } & jyviä & \multirow{2}{*}{\multicolumn{2}{|c|}{ - Barley }} & grain & 131 & 133 & 101 & 120 \\
\hline & & olkia & & & straw & 595 & 482 & 564 & 507 \\
\hline & \multirow[t]{2}{*}{ Kaura } & jyviä & \multirow[t]{2}{*}{ - } & \multirow[t]{2}{*}{ Oats } & grain & 200 & 209 & 207 & 165 \\
\hline & & olkia & & & straw & 696 & 702 & 676 & 607 \\
\hline \multirow[t]{6}{*}{1924} & \multirow[t]{2}{*}{ Turnipsi } & juuria & \multirow{2}{*}{\multicolumn{2}{|c|}{ - Turnip }} & roots & 9670 & 9340 & 9290 & 8420 \\
\hline & & naatteja & & & tops & 2110 & 1750 & 1750 & 1610 \\
\hline & \multirow[t]{2}{*}{ Lanttu } & juuria & \multirow{2}{*}{\multicolumn{2}{|c|}{ - Swede }} & roots & 4570 & 4120 & 3610 & 3680 \\
\hline & & naatteja & & & tops & 1660 & 1390 & 1320 & 1480 \\
\hline & \multirow[t]{2}{*}{ Sokerijuurikas } & juuria & \multirow{2}{*}{\multicolumn{2}{|c|}{ - Sugar beet }} & roots & 2046 & 2258 & 2623 & 2258 \\
\hline & & naatteja & & & tops & 4220 & 4170 & 3650 & 2970 \\
\hline \multirow[t]{8}{*}{1925} & Turnipsi & juuria & - & Turnip & roots & 7123 & 6846 & 7700 & 7741 \\
\hline & & naatteja & & & tops & 2430 & 2480 & 2130 & 2290 \\
\hline & Lanttu & juuria & - & Swede & roots & 4487 & 4415 & -4398 & 3775 \\
\hline & & naatteja & & & tops & 2350 & 2680 & 2280 & 2250 \\
\hline & Sokerijuurikas & juuria & - & Sugar beet & roots & 2786 & 3019 & 3173 & 3251 \\
\hline & & naatteja & & & tops & 5590 & 5650 & 4830 & 4940 \\
\hline & Kaura & jyviä & - & Oats & grain & 395 & 378 & 310 & 250 \\
\hline & & olkia & & & straw & 571 & 518 & 518 & 499 \\
\hline 1926 & Kesanto & & - & Fallow & & & & & \\
\hline 1927 & Vihantakaura & & - & Oats & green & 553 & 543 & 513 & 453 \\
\hline 1928 & 1. nurmi & timotei & - & 1st year ley & hay & 807 & 824 & 727 & 727 \\
\hline 1929 & 2. & , & - & $2 n d$, & , & 613 & 627 & 607 & 613 \\
\hline 1930 & 3. & , & - & $3 r d$ & , & 727 & 730 & 643 & 750 \\
\hline 1931 & Kaura & jyviä & 一 & Oats & grain & 258 & 263 & 264 & 252 \\
\hline & & olkia & & & straw & 473 & 447 & 427 & 427 \\
\hline & Ohra & jyviä & - & Barley & grain & 165 & 140 & 153 & 136 \\
\hline & & olkia & & & straw & 443 & 411 & 437 & 456 \\
\hline 1932 & Sokerijuurikas & juuria & 一 & Sugar beet & roots & 2460 & 2610 & 2690 & 2430 \\
\hline & & naatteja & & & tops & 6430 & 5840 & 5140 & 4540 \\
\hline & Lanttu & juuria & - & Swede & roots & 4640 & 4840 & 5250 & 4870 \\
\hline & & naatteja & & & tops & 2580 & 2580 & 2740 & 2330 \\
\hline & Turnipsi & juuria & - & Turnip & roots & 6130 & 6020 & 5520 & 5400 \\
\hline & & naatteja & & & tops & 1160 & 840 & 1000 & 910 \\
\hline & Peruna & & - & Potato & & 880 & 920 & 950 & 1050 \\
\hline 1933 & Vihantarehu & & - & Green food & & 240 & 255 & 233 & 185 \\
\hline & Ohra & jyviä & - & Barley & grain & 125 & 131 & 131 & 133 \\
\hline & & olkia & & & straw & 551 & 562 & 592 & 537 \\
\hline 1934 & 1. nurmi & heiniä & 一 & 1st year ley & hay & 801 & 754 & 795 & 799 \\
\hline 1935 & 2. & , & 一 & $2 n d$ & , & 690 & 690 & 678 & 695 \\
\hline 1936 & 3. & , & - & $3 r d$, & s & 399 & 440 & 459 & 456 \\
\hline 1937 & Kaura & jyviä & - & Oats & grain & 386 & 412 & 423 & 420 \\
\hline & & olkia & & & straw & 580 & 632 & 680 & 684 \\
\hline & Ohra & jyviä & - & Barley & grain & 356 & 313 & 370 & 363 \\
\hline & & olkia & & & straw & 556 & 584 & 720 & 708 \\
\hline & Kevätvehnä & jyviä & - & Spring wheat & grain & 312 & 301 & 320 & 350 \\
\hline & & olkia & & & straw & 468 & 480 & 540 & 568 \\
\hline
\end{tabular}


Sammutettua kalkkia, $\mathrm{kg} / \mathrm{ha}-\mathrm{Hydrate}$ of lime, $\mathrm{kg} / \mathrm{ha}$

$$
\begin{array}{lll}
0 & 1000 & 2000
\end{array}
$$

3000

\begin{tabular}{|c|c|c|c|c|c|c|c|c|}
\hline \multirow[t]{6}{*}{1938} & \multirow[t]{2}{*}{ Kaura } & \multirow{2}{*}{$\begin{array}{l}\text { jyviä } \\
\text { olkia }\end{array}$} & \multirow[t]{2}{*}{ - Oats } & grain & 280 & 285 & 277 & 261 \\
\hline & & & & straw & 496 & 531 & 551 & 513 \\
\hline & \multirow[t]{2}{*}{ Kevätvehnä } & \multirow{2}{*}{$\begin{array}{l}\text { jyviä } \\
\text { olkia }\end{array}$} & \multirow[t]{2}{*}{ - Spring wheat } & grain & 221 & 212 & 162 & 150 \\
\hline & & & & straw & 479 & 483 & 464 & 491 \\
\hline & \multirow[t]{2}{*}{ Ohra } & \multirow{2}{*}{$\begin{array}{l}\text { jyviä } \\
\text { olkia }\end{array}$} & \multirow[t]{2}{*}{ - Barley } & grain & 226 & 234 & 260 & 240 \\
\hline & & & & straw & 428 & 505 & 531 & 532 \\
\hline \multirow[t]{3}{*}{1939} & \multirow[t]{3}{*}{ Rehusokerijuu } & & - Fodder sugar & beet & & & & \\
\hline & & juuria & & roots & 1800 & 2840 & 3540 & 3380 \\
\hline & & naatteja & & tops & 1780 & 2380 & 2770 & 2810 \\
\hline \multirow[t]{6}{*}{1940} & \multirow[t]{2}{*}{ Kaura } & jyviä & \multirow[t]{2}{*}{ - Oats } & grain & 298 & 300 & 222 & 139 \\
\hline & & olkia & & straw & 615 & 619 & 619 & 482 \\
\hline & \multirow[t]{2}{*}{ Ohra } & jyviä & \multirow[t]{2}{*}{ - Barley } & grain & 98 & 172 & 164 & 134 \\
\hline & & olkia & & straw & 497 & 517 & 519 & 455 \\
\hline & \multirow[t]{2}{*}{ Kevätvehnä } & jyviä & \multirow[t]{2}{*}{ - Spring wheat } & grain & 177 & 187 & 159 & 152 \\
\hline & & olkia & & straw & 516 & 487 & 468 & 414 \\
\hline 1941 & Ei tuloksia & & - No results & & & & & \\
\hline 1942 & 1. nurmi & heiniä & - 1st year ley & hay & 610 & 620 & 635 & 605 \\
\hline
\end{tabular}

Liite II. Kalkituskoe 2. Sadot vuosittain $\mathrm{kg} / \mathrm{ha} \times 10^{-1}$

Appendix II. Liming test No. 1. Annual yields, $\mathrm{kg} / \mathrm{ha} \times 10^{-1}$.

Sammutettua kalkkia $\mathrm{kg} / \mathrm{ha}$ - Hydrate of lime, $\mathrm{kg} / \mathrm{ha}$

$\begin{array}{llll}0 & 1000 & 2000 & 3000\end{array}$

\begin{tabular}{|c|c|c|c|c|c|c|c|c|}
\hline \multirow[t]{2}{*}{1932} & Kaura & jyviä & - Oats & grain & 192 & 188 & 178 & 181 \\
\hline & & olkia & & straw & 605 & 584 & 603 & 577 \\
\hline \multirow[t]{2}{*}{1933} & Ohra & jyviä & - Barley & grain & 125 & 131 & 131 & 133 \\
\hline & & olkia & & straw & 551 & 562 & 592 & 537 \\
\hline \multirow[t]{2}{*}{1934} & Sokerijuurikas & juur. & - Sugar beet & roots & 2673 & 2838 & 2773 & 2790 \\
\hline & & naatteja & & tops & 5700 & 5680 & 5423 & 5975 \\
\hline \multirow[t]{2}{*}{1935} & Ohra & jyviä & - Barley & grain & 52 & 42 & 52 & 42 \\
\hline & & olkia & & straw & 344 & 330 & 327 & 311 \\
\hline 1936 & 1. nurmi & heiniä & - 1st year ley & hay & 733 & 728 & 753 & 733 \\
\hline 1937 & 2. & , & $-2 n d$ & , & 763 & 733 & 760 & 763 \\
\hline 1938 & 3. & , & $-3 r d$, & , & 708 & 658 & 705 & 688 \\
\hline 1939 & 4. & , & $-4 t h$ & , & 615 & 628 & 640 & 658 \\
\hline 1940 & 5. & , & $-5 t h$ & , & 418 & 415 & 400 & 403 \\
\hline \multirow[t]{2}{*}{1941} & Kevätvehnä & jyviä & - Spring wheat & grain & 119 & 113 & 136 & 117 \\
\hline & & olkia & & straw & 434 & 425 & 465 & 414 \\
\hline \multirow[t]{2}{*}{1942} & Porkkana & juuria & - Carrot & roots & 1884 & 1882 & $1905^{\circ}$ & 1868 \\
\hline & & naatteja & & tops & 426 & 458 & 474 & 461 \\
\hline \multicolumn{3}{|c|}{$1943-45$ Ei tuloksia } & - No results & & & & & \\
\hline \multirow{2}{*}{\multicolumn{2}{|c|}{1946 Kevätvehnä }} & jyviä & - Spring wheat & grain & 271 & 273 & 249 & 264 \\
\hline & & olkia & & strate & 530 & 540 & 555 & 531 \\
\hline
\end{tabular}


(1) Antrinen, O. 1957. Rahkasuon lannoitus- ja maanparannuskokeen tuloksia. (Referat: Ergebnisse eines Düngungs- und Bodenverbesserungsversuchs auf Sphagnum-Moor.) Valt.maatal.koetoim.julk. 155: 1-29.

(2) - - 1959. Saraturvesuon kalkitus- ja lannoituskokeen tuloksia. (Referat: Ergebnisse eines Kalkungs und Düngungsversuchs auf Seggentorfmoor.) Valt.maatal.koetoim.julk. 172: 1-32.

(3) Lindberg, H. 1903. Leteensuon kasvillisuus. S. suovilj. yhd. vuosik. 1903: 264-270.

(4) Pessi, Y. 1958. Rahkasuoviljelyksen kalkituksesta. (Summary: On the liming of cultivated Sphagnum bogs.) Suovilj. yhd. vuosik. 52-62: $29-32$.

(5) —- 1959. Kivennäismaan vaikutuksesta rahkasuon maanparannusaineena Leteensuon koeaseman pitkäaikaisten kenttäkokeiden perusteella (Summary: On the effect of mineral soil as a soil improving agent on Sphagnum bogs on the basis of prolonged field tests at Leteensuo Experimental Station.) Acta agr. fenn. 94. 14: 1-28.

(6) Rindell, A. 1903. Geologisessa mielessä huomattava tulos Leteensuon tutkimisesta. S. suovilj. yhd. vuosik. 1903: $271-275$.

(7) TuorilA, P. 1926. Maanparannuksen ja lannoituksen vaikutuksesta viljeltyjen soittemme happamuuteen ja tämän sekä maan kasvukunnon välisestä suhteesta. S. suovilj. yhd. vuosik. 30: $97-145$.

(8) Vesikivi, A. 1929. Suonsavetuksen ja -hiekoituksen taloudellisesta kannattavaisuudesta. (Referat: Uber die Rentabilität der Lehm- und Sandmischkultur auf Moorboden.) S. Suovilj. yhd. tiet. julk. 12: 1-131.

(9) —- 1933. Suomen Suoviljelysyhdistyksen koeasemien v:n 1932 koetuloksia: I. Leteensuon koeasema. S. suovilj. yhd. vuosik. 37: 45-48.

(10) — 1935. Suomen Suoviljelysyhdistyksen koeasemien v: 1934 koetuloksia. I. Leteensuon koeasema. S. suovilj. yhd. vuosik. 39: 59-78.

\section{S U M M A R Y}

\section{THE RESULTS OF LIMING TESTS ON FEN AT LETEENSUO}

by YRJö PESSI

\section{Test area and test projects}

A detailed description of the plant cover of the bog region in question has been given by LINDBERG (13), while its geological aspects have been treated by RINDELL (6). The peat of the test area is forest sedge peat and the bog type prior to clearing was wooded swamp with herbs and grasses.

The chemical qualities of the peat adjacent to the test areas have been illustrated by RINDELL. These results are found in detail in the publication by VEsikivi (8, p. 32). It may be mentioned in this connection that the $\mathrm{CaO}$ of the soil layer $20 \mathrm{~cm}$ in height has been $5858 \mathrm{~kg}$ per hectare, corresponding thus to the $\mathrm{CaO}$ content of nearly 12 tons of ground limestore.

The test begun in 1908 was established by A. Rindell and E. F. Simola, and the test started in 1932 by A. Vesikivi. The tests have been conducted by E. F. Simola (1908-1917), E. A. Malm (19181919), A. Vesikivi (1920-1943), J. Törmä (1944), and U. E. Hirvensalo (1945-1946).

The question of liming on fen at the Leteensuo Experimental Station is studied in the following on the basis of two prolonged liming tests.

Liming test No. 1. - The test area had been cleared for cultivation and provided with wooden drains of square cross-section in 1904. The phosphate and potassium fertilizing had been annual, the phosphate fertilizing being equivalent to about $200-300 \mathrm{~kg}$ superphosphate and the potassium fertilizing to $100-200 \mathrm{~kg} 50 \%$ potassium salt per hectare. Mineral soil had not been used as a soil improvement material. The limings were performed according to plan four times $(0,1000,2000,3000 \mathrm{~kg}$ slaked lime per hectare) that is in $1907,1911,1920$, and 1940. 
Liming test No 2. - The test area had been cleared for cultivation in 1904. The following year sand had been given in a quantity of $400 \mathrm{~m}^{3}$ per hectare as soil improvement material. Cultivation had begun the same year. The liming test was arranged as late as 1932 when the liming was performed according to plan $(0,1000,2000$, and $3000 \mathrm{~kg}$ slaked lime per hectare). The annual fertilizing had been similar to that of the preceding test.

TuORILA (7) has studied the changes in soil acidity resulting from the liming in the test begun in 1908 . The $\mathrm{pH}$-figure was 4.9 without lime and $5.25,5.55$, and 6.35 with increasing liming.

\section{Crop yield results}

The weather conditions of the test years have been described in a previous publication (PESSI 5).

The annual crop yield results of the test can be seen in Tables I and II in the Appendix. Treating the test results in addition to the annual mean values, the significant crop yield differences are counted only if the F-value has at least one asterisk.

\section{Grass ley}

Tables 1 and 2 show the average annual crop yields. The grass crops have been timothy-dominated. The results show that liming has neither increased nor decreased the crop yields. On the sedge peat bog at Ruukki, on the other hand, where the lime content of the soil before the fertilizing and liming test was about $4500 \mathrm{~kg} \mathrm{CaO}$ per hectare, liming has increased the crop yields (2, p. 14).

\section{Cereals}

Table 3 and Figure 1 show the average annual yield results of oats and barley. It is noticeable that liming-thas decreased the grain yields of oats in the same way as in the experiment at Ruukki (2, p. 16). On the other hand liming has neither increased nor decreased the grain yield of barley.

\section{Root crops}

Table 4 and Figure 2 show the yields of root crops. It can be seen that lower liming quantities have increased the root yields of sugar beet while the highest liming quantity has decreased it. On the root yields of swede and turnip liming has had no particular effect. Peculiar to the yields of tops of all root crops is that liming has lowered them.

\section{Quality of the yield}

Studies dealing with the quality of yield are scarce. From a space of two years there exist only the analyses of the sugar content of sugar beet. In 1924 the sugar content was $15.6 \%$ in the treatment without lime and $15.6,15.6$, and $14.4 \%$ when the quantity of lime was increased. In 1932 the correspond. ing numbers were $16.7,14.0,14.8$, and $16.0 \%$. Thus liming has not had a significant effect on the sugar content.

\section{Conclusions}

On fen the peat of which is forest sedge peat and where in a soil layer $20 \mathrm{~cm}$ in height the CaO has been nearly $6000 \mathrm{~kg}$ per hectare, the effect of liming has varied depending on the test plant. The timothy-dominated grass ley, the grain yield of barley, and the root yields of swede and turnip have not been influenced by liming in a high degree. The root yields of sugar beet are increased by liming altr.ough the top quantity of lime has a lowering effect. The grain yield of oats is distinctly decreased by liming. The yields of root crop tops decrease with an increase in the liming. 